19

\title{
Сдвиг пика локализованного плазмонного резонанса в гранулированных пленках золота на поверхности а-С : H
}

\author{
() Е.А. Коншина, Д.П. Щербинин, М.M. Abboud, И.А. Гладских \\ Университет ИтМО, \\ 197101 Санкт-Петербург, Россия \\ e-mail: eakonshina@mail.ru
}

Поступила в редакцию 02.03.2018 г.

Изучены спектры оптической плотности гранулированных пленок золота толщиной $2 \mathrm{~nm}$, осажденных на поверхность тонких пленок аморфного гидрогенизированного углерода (a-C:H) на кварцевых подложках. Показан сдвиг пика локализованного поверхностного плазмонного резонанса в коротковолновую область спектра на $32 \mathrm{~nm}$ при увеличении ширины оптической щели а-C:H-пленок от 0.8 до $2.4 \mathrm{eV}$. Одновременно наблюдалось увеличение интенсивности и сужение полосы плазмонного резонанса в спектрах наноструктур золота. Это свидетельствует о влиянии структурных особенностей а-С:Н-пленок на формирование гранулированных пленок золота на их поверхности.

DOI: $10.21883 / \mathrm{OS} .2018 .08 .46372 .63-18$

\section{Введение}

В настоящее время золотые наночастицы широко используются в оптических биосенсорах благодаря их химическим и физическим свойствам, а также хорошей биосовместимости [1-6]. Разработаны концепции использования объемных и локализованных поверхностных плазмонов и принципы работы обоих методов зондирования для биосенсоров [1]. Отправной точкой при создании оптических биосенсоров является настройка оптического отклика металлических наночастиц путем контроля их размера, формы и окружающей среды. Локализованный поверхностный плазмонный резонанс (ЛППР) чувствителен к изменению граничных условий металлических наночастиц. Поэтому управлять оптическим откликом можно путем изменения граничных условий. Усиление интенсивности и сдвиг пика ЛППР в коротковолновую область спектра на $16 \mathrm{~nm}$ наблюдались при отжиге в спектрах гранулированной наноструктурированной серебряной пленке на поверхности тонкой пленки аморфного гидрогенизированного углерода (a-C:H) [7]. В то время как внедрение серебряных наночастиц в углеводородную матрицу вызывало красный сдвиг пика плазмонного резонанса, который зависел от содержания атомов Ag в объеме, а не от свойств аморфного углерода [8].

Оптические и диэлектрические свойства а-C:H-пленок, полученных в плазме тлеющего разряда, хорошо изучены. Они зависят от относительного содержания атомов углерода в $s p^{2}$ - и $s p^{3}$-гибридизации их электронных оболочек [9]. Электронные свойства $\mathrm{a}-\mathrm{C}: \mathrm{H}$ определяются $\pi-\pi$-электронными переходами в отдельных наноразмерных кластерах, присутствующих в структуре пленок, и степенью делокализации в них $\pi$-электронов. Центрами кристаллизации металлических наночастиц на поверхности а-С:Н-пленок служат $\pi$-кластеры. С помощью декорирования поверхности таких пленок остров- ковыми пленками серебра было показано, что размер $\pi$-кластеров может изменяться от 4 до $100 \mathrm{~nm}$ в зависимости от условий получения, толщины пленок и исходного углеводорода [10].

В настоящей работе мы исследовали изменения спектров оптической плотности гранулированных наноструктурированных пленок золота на поверхности тонких

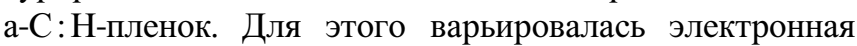
структура $\mathrm{a}-\mathrm{C}: \mathrm{H}$ путем изменения условий осаждения пленок в плазме тлеющего разряда и определялась ширина оптической щели пленок. Изучалась зависимость параметров полосы локализованного поверхностного плазмонного резонанса (положение пика, интенсивность и полущирина полосы) в гибридных тонкопленочных золотых наноструктурах от оптической ширины щели a-C:Н-пленок.

\section{Материалы и методы эксперимента}

Пленки а-C:Н-получали химическим осаждением паров толуола в плазме тлеющего разряда на постоянном токе, поддержимаемой магнетронной плазмой, локализованной вблизи анода [9]. Мощность тлеющего разряда варьировалась в интервале 0.6-6 W при изменении давления в вакуумной камере от 1 до $4 \cdot 10^{-4}$ Torr. Толщина a-C:Н-пленок на кварцевых подложках была около $50 \mathrm{~nm}$.

Для получения пленки золота использовали метод термического испарения в вакуумной камере (PVD 75 Kurt J. Lesker) при остаточном давлении $\sim 10^{-7}$ Torr и комнатной температуре. Гранулированную пленку Аu с эффективной толщиной $2 \mathrm{~nm}$ осаждали на поверхность всех исследуемых образцов а-С:Н-пленок в одном процессе.

Ширина оптической щели а-С:Н-пленок определелялась с помощью спектров оптической плотности, по- 
Ширина оптической щели а-С:Н-пленок и параметры спектров поглощения гланулированных наноструктур $\mathrm{Au}$ на их поверхности

\begin{tabular}{c|c|c|c|c|c}
\hline Образец & Структура & $\begin{array}{c}E_{T}(\mathrm{a}-\mathrm{C}: \mathrm{H}), \\
\mathrm{eV}\end{array}$ & $\begin{array}{c}\lambda, \\
\mathrm{nm}\end{array}$ & $D$ & $\begin{array}{c}\mathrm{FWHM} \\
\mathrm{nm}\end{array}$ \\
\hline 1 & quartz/a-C $: \mathrm{H} / \mathrm{Au}$ & 0.8 & 644 & 0.099 & 293 \\
2 & quartz/a-C:H/Au & 0.95 & 639 & 0.119 & 307 \\
3 & quartz/a-C:H/Au & 1.5 & 632 & 0.130 & 304 \\
4 & quartz/a-C:H/Au & 2.4 & 612 & 0.135 & 267 \\
5 & quartz/Au & - & 659 & 0.127 & 320
\end{tabular}

лученных в интервале 200-1000 nm. Измерения спектров проводились с помощью спектрофотометра СФ-56 (ЛОМО, Санкт-Петербург). Ширину оптической щели пленок по аналогии с аморфными полупроводниками можно оценить, используя уравнение Тауца

$$
(\alpha E)^{1 / 2}=B^{1 / 2}\left(E-E_{T}\right),
$$

где $E$ - энергия фотона, $B$ - постоянная, пропорциональная плотности электронных состояний, $\alpha-$ натуральный коэффициент поглощения. Для определения ширины оптической щели строились зависимости $(\alpha E)^{1 / 2}$ от $E$. Точка пересечения экстраполяционной прямой с осью абсцисс соответствует оптической щели пленки (энергии Тауца).

\section{Результати и их обсуждение}

Спектры оптической плотности $(D)$ a-C:Н-пленок, полученных в разных условиях, показаны на рис. $1, a$. На рис. $1, b$ приведены зависимости $(\alpha E)^{1 / 2}$ от $E$ для этих $\mathrm{a}-\mathrm{C}: \mathrm{H}$-пленок. Полученные значения оптической щели $\mathrm{a}-\mathrm{C}: \mathrm{H}$-пленок даны в таблице.

На рис. 2 показаны спектры оптической плотности гранулированных пленок золота, нанесенных на поверхность иследованных а-С:Н-пленок. Параметры спектров оптической плотности, приведенных на рис. 2, даны в таблице. Наблюдалось смещение пика ЛППР, изменение интенсивности и полуширины полосы поглощения (FWHM - full width at half maximum) спектров гранулированных золотых пленок на поверхности а-С:Н-пленок по сравнению со спектром этих пленок на кварцевой подложке. Наибольший гипсохромный сдвиг пика плазмонного резонанса в спектрах на рис. 2 характерен для образца № 4 (таблица) относительно спектра $\mathrm{Au}$ на поверхности чистого кварца, который составил $47 \mathrm{~nm}$. Для этого образца характерна также наибольшая интенсивность пика плазмонного резонанса и наименьшая полуширина полосы в спектре на рис. 2. Условия

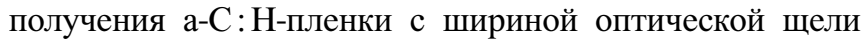
$2.4 \mathrm{eV}$ (таблица, образец № 4) отличались от образцов № 1-3 более высоким давлением в вакуумной камеpe $\left(4 \cdot 10^{-4}\right.$ Torr $)$ и мощностью тлеющего разряда $(6 \mathrm{~W})$, что обеспечивало наибольшую скорость осаждения и
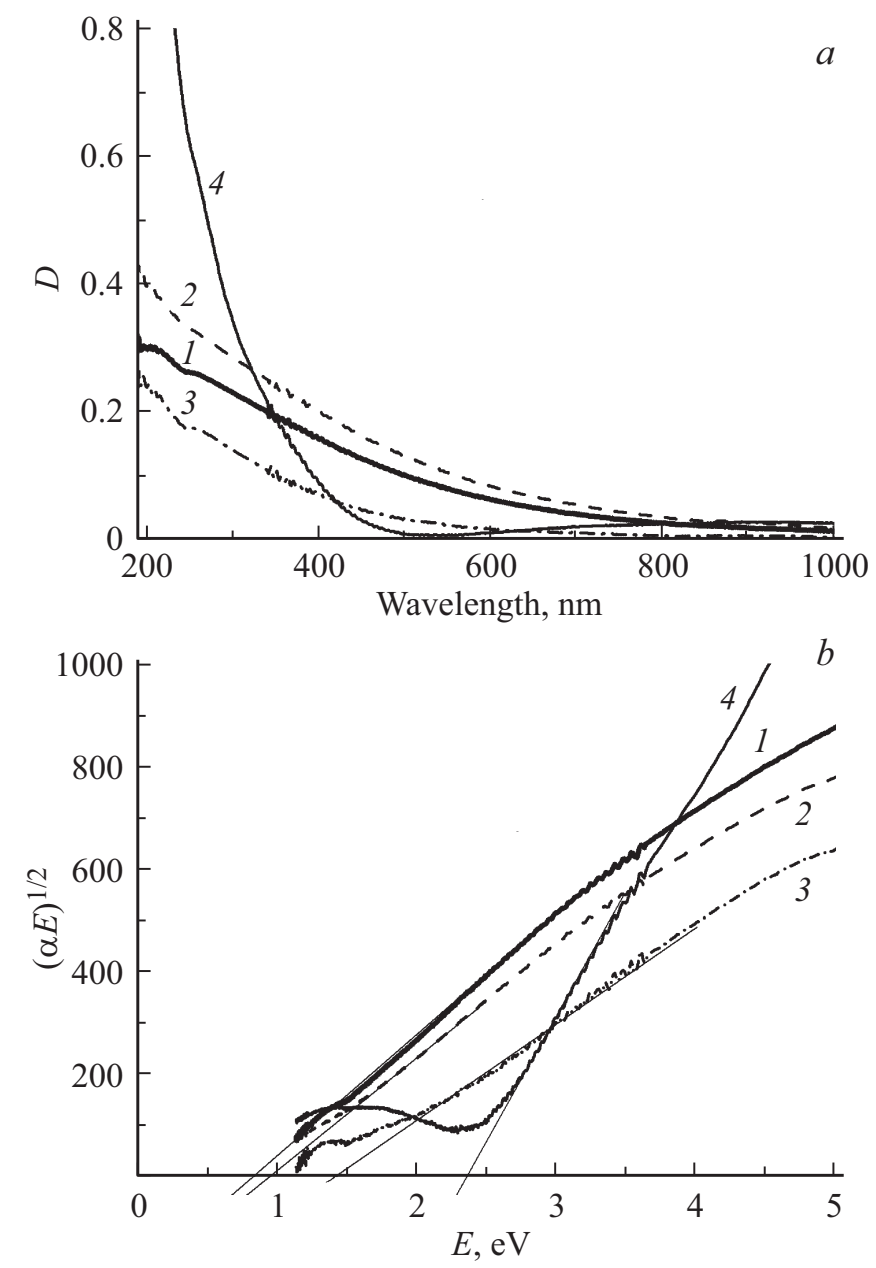

Рис. 1. Спектры поглощения а-C:Н-пленок, осажденных на кварцевые подложки $(a)$. Зависимости $(\alpha E)^{1 / 2}$ от $E$ для этих a-C:Н-пленок $(b)$. Номера спектров соответствуют образцам, указанным в таблице.

наименьший показатель преломления пленки. Как было показано ранее, показатель преломления а-C:Н-пленок, полученных из паров толуола, уменьшается от 1.8 до 1.6 с увеличением скорости осаждения [9]. Смещение пика ЛППР приблизительно линейно с малыми изменениями показателя преломления [11]. Уменьшение показателя преломления пленок может приводить к синему сдвигу и увеличению плазмонного пика наночастиц [12].

С уменьшением ширины оптической щели а-C:H-пленок интенсивность плазмонного пика понижалась (таблица, образцы № 1 и № 2) по сравнению со спектром гранулированной пленки $\mathrm{Au}$ на поверхности кварца (образец № 5). Это может быть вызвано увеличением фактора заполнения для этих образцов, т. е. отношением суммы площадей наночастиц $\mathrm{Au}$ к площади образца в результате укрупнения отдельных наночастиц $\mathrm{Au}$ и уменьшением промежутков между ними. Сдвиг плазмонного пика составил $32 \mathrm{~nm}$ при изменении оптической ширины щели от 0.8 до $2.4 \mathrm{eV}$ (рис. 2, вставка). Увеличение ширины оптической щели коррелирует с 


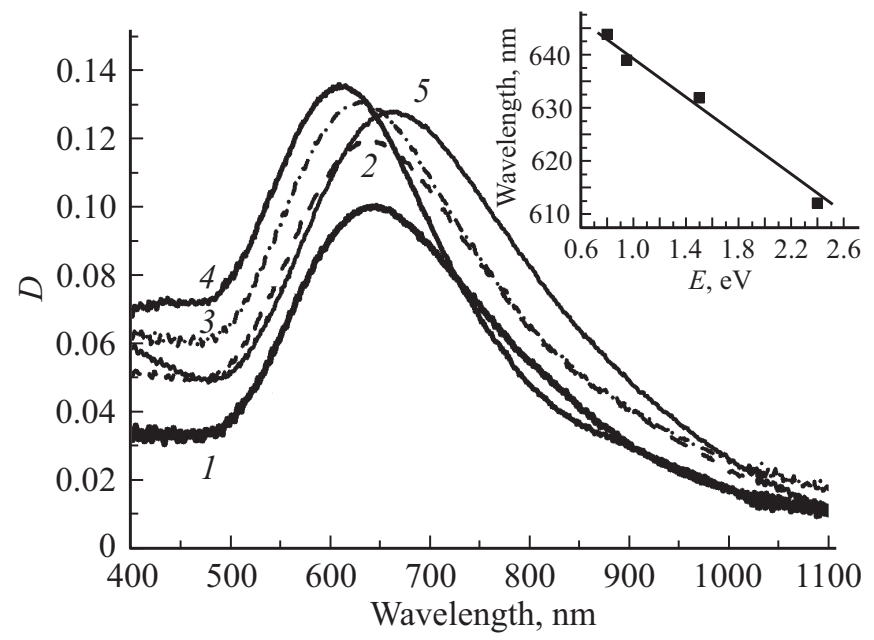

Рис. 2. Спектры поглощения гранулированных пленок золота на поверхности а-С:Н-пленок. На вставке показана зависимость длины волны плазмонного пика от оптической ширины щели а-C:Н-пленок. Номера спектров соответствуют образцам в таблице.

ростом удельного сопротивление а-С:Н-пленок [9]. Поэтому вероятность локализации $\pi$-электронов в отдельных небольших кластерах на поверхности а-С:Н-пленок и увеличение расстояния между ними растет с увеличением ширины оптической щели. Такая структура a-C:Н-пленок может способствовать уменьшению фактора заполнения для гранулированных золотых пленок и локализации электронов в плазмонных наночастицах. Об этом свидетельствует также сужение полосы и повышение интенсивности пика плазмонного резонанса, наблюдаемое экспериментально. Изменения параметров спектров гранулированных пленок золота для образцов № 1-4 (таблица) коррелируют с изменением электронной структуры и оптических свойств а-C:Н-пленок. Таким образом, можно заключить, что контролировать параметры спектров ЛППР золотых наноструктур можно, изменяя электронную структуры а-C:Н-пленок на границе раздела.

\section{Заключение}

Мы исследовали гранулированные наноструктурированные пленки золота, осажденные на поверхность тонких а-С :Н-пленок на кварцевых подложках. Полученные результаты свидетельствут о возможности управления сдвигом пика локализованного плазмонного резонанса в гранулированных золотых наночастицах, изменяя оптические и диэлектрические свойства а-C:Н-пленок на границе раздела. Смещение пика плазмонного резонанса в коротковолновую область спектра на $32 \mathrm{~nm}$ было получено с увеличением ширины оптической щели $\mathrm{a}-\mathrm{C}: \mathrm{H}$-пленок от 0.8 до $2.4 \mathrm{eV}$. Осуществление управления положением, интенсивностью и полушириной полосы локализованного поверхностного плазмонного резонанса в спектрах гранулированных золотых наноструктур позволит расширить возможности для создания новых оптических биосенсоров и других оптических устройств на их основе.

Работа выполнена при государственной финансовой поддержке ведущих университетов Российской Федерации (субсидия 08-08)

\section{Список литературы}

[1] Guo X.J. // Biophotonics. 2012. V. 5. P. 483. doi 10.1002/jbio.201200015

[2] Saha K., Agasti S.S., Kim C., Li X., Rotello V.M. // Chem. Rev. 2012. V. 112. P. 2739. doi 10.1021/cr2001178

[3] Nie L., Liu, Ma P., Xiao X. // J. Biomed. Nanotechnol. 2014. V. 10. P. 2700. doi 10.1166/jbn.2014.1987

[4] Shah M., Badwaik V.D., Dakshinamurthy R. // J. Nanosci. Nanotech. 2014. V. 14. P. 344.

[5] Libo N., Fuhua L., Peng M., Xiangyun X. // J. Biomed. Nanotechnol. 2014. V. 10. P. 2700. doi 10.1166/jbn.2014.1987

[6] Kim J.E., Choi J.H., Colas M., Kim D.H., Lee H. // Biosens. Bioelectron. 2016. V. 80. P. 543. doi 10.1016/j.bios.2016.02.015

[7] Щербинин Д.П., Коншина Е.А., Полищук В.А. // Опт. и спектр. 2016. Т. 120. В. 4. С. 124; Shcherbinin D.P., Konshina E.A, Polishchuk V.A. // Opt. Spectrosc. 2016. V. 120. B. 4. P. 622. doi 10.7868/S0030403416040218

[8] Meskinis S., Ciegis A., Vasiliauskas A., Tamuleviciene A., Slapikas K., Juskenas R., Niaura G., Tamulevicius S. // Appl. Surf. Sci. 2014. V. 317. P. 1041. doi 10.1016/j.apsusc.2014.09.032

[9] Konshina E.A. // Crystalline and Non-crystalline Solids. InTech. 2016. P. 126. http://dx.doi.org/10.5772/62704

[10] Коншина Е.А., Туровская Т.С. // ЖТФ. 1998. Т. 68. В. 1. C. 106; Konshina E.A., Turovskaya T.S. // Tech. Phys. 1998. V. 43. N 1. P. 97.

[11] Mayer K.M., Hafner J.H. // Chem. Rev. 2011. V. 111. P. 3828. doi $10.1021 / \mathrm{cr} 100313 \mathrm{v}$

[12] Noguez C. // J. Phys. Chem. C. 2007. V. 111. N 10. P. 3806. doi $10.1021 /$ jp066539m. 